\title{
How practices are embracing corporate social responsibility
}

Practice Plan's Sales and Marketing Director, Nigel Jones, caught up with Mark Topley, ${ }_{1}^{1}$ of CSR Certification Ltd, to talk about corporate social responsibility and how dental practices are incorporating it into their businesses.

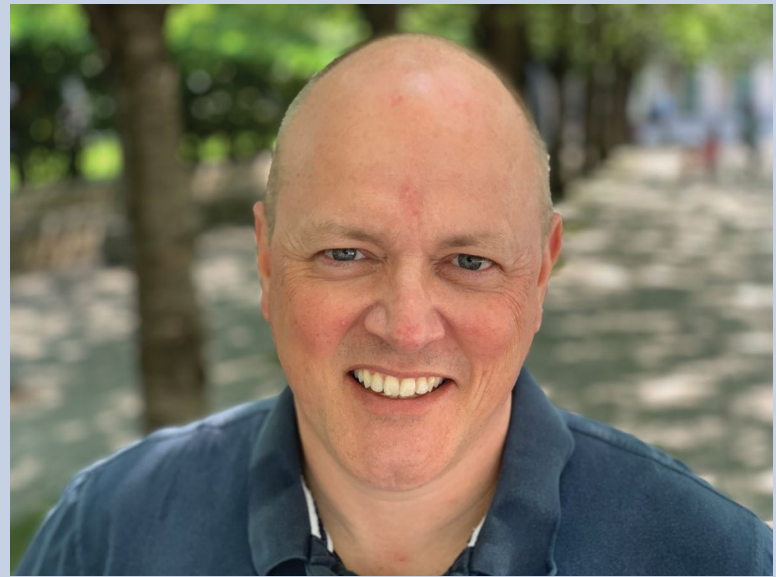

Mark Topley

NJ: Hi Mark, can you tell us about your work on Corporate Social Responsibility (CSR)?

MT: While I was the CEO of Bridge2Aid, which helps to provide dental care in some of the world's poorest countries, I came across CSR in East Africa, and saw how companies were putting policies in place that had a positive impact on the communities they serve. So, when I left Bridge2Aid, I brought together the lessons I had learned from how big firms introduced CSR, and set up an organisation called CSR Certification Ltd, helping businesses bring it into their everyday working.

NJ: How do larger firms view CSR and how has it been trying to implement it with smaller businesses, such as dental practices?

MT: We began with market education to help practices understand why CSR is important and how it can be implemented successfully. Many practices I've come across have introduced CSR because they feel it is the right thing to do, and many have said: 'I want to give something back.

Bigger firms have embraced CSR for a lot longer, because they have noticed macro trends in consumer expectations, and have seen that nine in ten people now expect it to be a part of a business' operations, rather than a charitable add on. Employees now think the same, and of the millennial generation, around $75 \%$ are looking for CSR in a future employer, and they are willing to work for less money if they are working for a purpose. Others, both big and small firms, want to create a legacy and something that will matter in the future, and they ask themselves: how can we put this community in a better place?

\section{NJ: How has the pandemic impacted CSR?}

MT: It has probably accelerated it by five to ten years. People have had more time to look at implementing CSR, time they wouldn't have had pre-pandemic. Also, the pandemic has made people realise that they have a role to play in their communities as corporate citizens, something they might not have considered before. Over the last 18 months, I've seen practices step up in terms of PPE supply, reassuring communities and sign-posting people to various services. And despite the economic challenges post-pandemic, businesses are still taking CSR more seriously. Topics such as the environment and sustainability remain on top of people's agendas, and they want to play their part.

NJ: So, when a practice is thinking about where their emphasis should be and what they should focus on with their whole CSR strategy, how do you help them?

MT: We start with a mission statement framework, which involves the questions: why are we doing this? Why is it important? What impact do we have on the world? What are we trying to get to, and what's my role in this?

Once we're clear on that, we have the soil in which to plant our CSR initiatives. We have three types of initiatives which include people and ethics, then environment and sustainability, so we look at things like carbon footprint and biodiversity. Sometimes, practices are doing these things; it's just about putting a plan in place to ramp them up.

The other is charity and communication, so we brainstorm ideas the practice may have for charitable causes. What we do is break things down into something that is simple and can be managed by one person for a couple of hours a week.

What I say to people who are overwhelmed by CSR is that it isn't a whole new thing you need to introduce; it is about changing the way you do a lot of little things.

\section{NJ: Have you seen CSR have a positive impact on practices that have} embraced it?

MT: Yes, I've seen the positive impact CSR can have on businesses and the communities they serve. One practice worked with a foodbank, talked about it on social media, and it got lots of engagement. Many practices put up pictures of teeth, which is what the business is about, but it doesn't give the customer a sense of who you are as a team.

From the outside, things like working with a foodbank or a charity raffle helps with your reputation, shows people you're doing good and from that they may choose to come to you for treatment. Another positive of CSR that people are seeing is that it helps them make savings. Introducing measures through CSR, such as using renewable energy and saving power, can help to save your practice money in the long term.

NJ: Thanks for taking the time to talk about such a key topic. 